\title{
Prudential Value or Well-Being
}

\author{
Raffaele Rodogno \\ Philosophy and History of Ideas \\ Aarhus University \\ Jens Chr. Skous Vej 7 \\ 8000, Aarhus C \\ Denamrk \\ filrr@cas.au.dk
}

Penultimate Draft to appear in Oxford Handbook of Value: The Affective Sciences of Values and Valuation. Tobias Brosch \& David Sander (eds.) Oxford University Press

\begin{abstract}
Well-Being or prudential value is one of the things we typically consider when figuring out what options, experiences, pursuits, or kinds of lives to pursue or choose. What's best for me or in my best interest, the life of pleasure or the pursuit of knowledge? In this chapter I begin by introducing the linguistic contours of prudential value. I then present a sceptical challenge to the effect that well-being is not a sui generis kind of value but rather always reducible to absolute value. I argue that well-being cannot be an absolute value and is best understood as a relational value, and explain how this view connects and is compatible with views that assign to well-being radically different places on the subjectivity/objectivity spectrum. I then show how philosophy most broadly systematizes well-being claims in two main theoretical families, formal and substantive. Formal theories individuate those properties that purportedly determine whether something is good or bad for one (the prudential value-makers), while substantive theories individuate those things that purportedly make someone's life go better for them (pleasure, friendship, virtue, etc.). I then illustrate the main players from both theoretical families, namely, hedonism, desire satisfaction theory, perfectionism, objective list theories, and happiness theories. Finally, I show how recent work in psychology and affective science should be viewed as the more or less explicit empirical articulation of these philosophical theories.
\end{abstract}

Well-Being, Prudential value, hedonism, happiness, desire satisfaction, perfectionism, relational value, Objective list, Subjective well-being, Objective happiness, Eudaimonism

\section{The language of well-being}

Kim, a high school graduate, is considering a number of rather unsurprising questions: Should I become a doctor, endure a long period of study without an income, but hopefully have a meaningful job with a good income at the end? What are my chances of succeeding? Would I enjoy my studies and then my job? And what would my life look like if I did succeed? Would I have time to keep up mountain climbing and see my friends? And would I eventually have time for a rich family life? Perhaps it would be better for me to work as a postman, take the morning shift, be finished at 2pm, have time to go mountain climbing after work, and meet up with my friends in the evening, if I feel 
like it. Surely work, of whichever kind, can never be as good for me as climbing and being with the people I care about. Or should I rather devote my life to those in need, or to intellectual and artistic achievement? Are these kinds of pursuits at all good for me?

When answering questions such as these, moral and perhaps other kinds of values may surely be at play. Yet it is at least as clear that these common questions are motivated in large part by a concern with well-being or prudential value. The idea of prudential value is often found in the literature in these terms:

[Well-Being is] what we have when our lives are going well for us, when we are living lives that are not necessarily morally good, but good for us' (Tiberius 2006: 493, italics in original)

\section{Or again:}

It is commonly supposed that there is a single notion of individual well-being that... serves as a basis for the decisions of a single rational being, at least for those decisions in which he or she alone is concerned (that is to say, in which moral obligations and concern for others can be left aside). (Scanlon, 1998: 108)

Four general points about well-being arise from these quotes.

1. The terminology of well-being. Questions about the prudential value or disvalue of lives or, alternatively, questions about what in an individual's life is of prudential value or disvalue ${ }^{1}$ are also discussed in terms of 'well-being'- and 'ill-being', 'welfare', 'benefit' and 'harm', 'happiness' and 'misery', what is 'good for' and 'bad for' an agent, as well as in terms of 'flourishing' or 'thriving', 'a person's' interest', or a 'person's good' or 'personal good'. Generally, that is, there is an assumed relation of synonymy standing among these expressions. ${ }^{2}$ While we shall for the most part go along with this presumption, as we shall see in Section 2, there are reasons not to equate conceptually 'happiness' and 'well-being'. In fact, the pair 'good for' and 'bad for' also deserves special attention. These expressions are often used in connection with the good or perfect functioning of organisms and artefacts, as in 'lubricant is good for the engine', 'rust is bad for the car', and 'smoking is not good for people'. By these expressions, we typically mean that certain things are good or bad for the proper functioning of the organism or artefact in question. This is not the sense of 'good for' and 'bad for' at issue with prudential value. Or better, it is not conceptually the case that well-being is to be equated with good or perfect functioning in this sense. This latter claim, if true, needs substantive argument. ${ }^{3}$ In the absence of that, it may well be true that smoking is bad for my organism but prudentially good for me. ${ }^{4}$

2. The axiological nature of prudential value. As some of the above remarks suggest, at the conceptual level, prudential value is neither moral, nor aesthetic, nor perfectionist value. It is arguably a kind of value irreducible to any other kind, which may nonetheless stand in various

\footnotetext{
${ }^{1}$ Rodogno (in press) argues that these two questions, though connected, are distinct.

2 Rosati (2006, pp.108-109) offers reasons that relate to her specific prudential theory to prefer 'personal good' over 'flourishing', 'welfare', and 'well-being'. Raz (1986, pp.294-5) draws a distinction between wellbeing and self-interest, where the former is treated as "the general term for evaluating success in life" and the latter is a largely biological notion.

${ }^{3}$ Substantive argument here may amount to a simple intuition to the effect that an individual's well-being consists in its perfect functioning.

${ }^{4}$ Rosati (2009a) contains an excellent discussion of the various meaning of "good for" and their relation to the concept of well-being.
} 
substantive relations to them. Hence for example, if we admit that pleasure has prudential value, the alleged truth of the claim 'Evil pleasures are not good for us' cannot be conceptual and must be argued substantively. As we shall see (Section 2.1), however, the claim that well-being is not reducible to other values has been the object of sustained scepticism.

3. The normativity of well-being. There is widespread agreement to the effect that well-being is, both, a descriptive and a normative concept. As Tiberius and Plakias (2008, p.402) claim, the term 'well-being' "aims to pick out an empirical phenomenon that can be measured, compared, and (one hopes) realized in people's lives: to achieve well-being is to enjoy a certain kind of life or set of experiences that we can investigate and influence." Yet, 'well-being' also has normative significance, i.e., it involves reasons: if $A$ is better for you than $B$, ceteris paribus, you have more reason to do $A$. While very few disagree with this claim, ${ }^{5}$ growing disagreement is to be encountered with respect to the kind of normativity well-being is taken to involve.

The standard view is that well-being is an agent-relative value, i.e., it gives reasons to the agent whose well-being it is. Hence, if something increases my well-being, then $I$ have reason to desire it and pursue it, and similarly for you and your well-being, him and his well-being, etc. In each case, the reason-giving fact for the agent is that his or her good would be contributed to or not diminished. It is less clear, however, what the standard view would hold with regard to the agent-neutrality of well-being. Agent-neutrality here means that everyone has reason to promote everyone's wellbeing, including his or her own. For every agent, the reason-giving fact is that someone's good would be promoted or not diminished. ${ }^{6}$

4. The limits of the concept of well-being. This question can be understood at the level of the subjects of well-being (Rodogno 2010) - what kinds of entities can have well-being beside human beings? Non-human animals? Plants and trees? Microbes?-or it can be understood at the level of the kinds of states, activities, or choices that can be counted as enhancing someone's well-being. One important discussion here is the interplay between well-being and self-sacrifice. One of the central features of the idea of well-being is that an individual's well-being or self-interest may well compete or come into conflict with other demands placed on the individual. Perhaps the most common conflict of this kind is the one between one's well-being or self-interest, on the one hand, and one's moral duties, on the other. When such conflicts arise, individuals may be required to selfsacrifice, to forego their self-interest, in order to fulfill their overriding moral duties. This picture does seem in line with our moral phenomenology, as when we only recalcitrantly comply with our duties. On this picture, the respective extensions of 'well-being' and 'self-sacrifice' exclude each other. At least on modern conceptions, it follows that any account of well-being that systematically describes as self-interested actions that are self-sacrificing will attribute to 'well-being' a scope that is too wide. Such accounts are affected by a "scope problem".

With these basics in mind, we are ready to broach philosophical analyses of well-being, in the next section, and the theoretical connections between the philosophy and the psychology of well-being, in the section after that.

\section{Well-Being in Philosophy}

\footnotetext{
${ }^{5}$ Kraut (2007, p.62) is the only exception known to me.

6 The claim that well-being is an agent-relative value has recently been challenged (Darwall 2002), and its agent neutrality has been more clearly defended (Darwall 2002; Reagan 2004; Rosati 2008).
} 
Philosophical discussion of well-being has traditionally focussed on so-called theories of well-being. These are of two kinds: formal (or explanatory) and substantive (or enumerative). ${ }^{7}$ A theory counts as substantive only if it directly attributes prudential value to certain items (e.g. kinds of mental states, relationships, states of affairs, activities, etc.). Theories of this kind provide answers to the question: Which things make someone's life go better for them? A substantive hedonist, for example, is someone who claims that only pleasurable mental states are prudentially good where nonhedonists would also mention other goods (e.g., friendship, knowledge, autonomy, etc.) that are taken by them to be irreducible to pleasurable mental states.

A theory counts as formal only if it tries to identify why something is prudentially good, or, as some would say, only if it identifies the prudential or good-for value maker. Such a theory provides answers to the question: What makes something good for the individual? A formal hedonist, for example, will hold that pleasantness, and only pleasantness is what makes substantive goods what they are. Others, however, will argue that it is the satisfaction of an individual's desires that makes something prudentially good, and so on.

The two kinds of theory stand in a complementary relation. Hence a substantive hedonist will typically also be a formal hedonist, holding that pleasantness is what makes pleasure good for an individual. Yet, it is logically possible and in fact a live option to combine substantive hedonism with other formal outlooks. One may for example hold that what makes pleasurable mental states prudentially good is the fact that they fulfil one of the individual's desires.

Theories of well-being are also often categorized as being either subjective or objective. Subjectivism states that nothing can intrinsically enhance the quality of an individual's life unless that person desired or endorsed that thing, or unless the person would desire or endorse that thing under idealized conditions, i.e. perfect rationality and/or full-information (Arneson 1999; Sumner 1996). Objective theories do not include such a requirement. Hence, something may be good for an individual even in the absence of a relevant pro-attitude on his or her behalf.

Finally, theories of well-being are often divided along another dimension, which we shall call mentalism or, alternatively, experientialism. A theory is mentalist or experientialist if it states that something can affect an individual's well-being only to the extent to which the individual experiences that thing. Hence while pleasurable experiences would clearly be good candidates for mentalist views, on such views the fact that unbeknownst to me my wife is cheating on me cannot as such affect my well-being. Non-mentalist or non-experientialist accounts could in principle accommodate also such facts.

More recently, some philosophers (Darwall 2002; Rosati 2006) have moved beyond theories of well-being of the kinds described above and have focussed instead on conceptual analyses of wellbeing compatible with a number of such theories. While we will not have the opportunity to discuss them here, these analyses afford much needed answers to the sceptical challenge that well-being is in fact reducible to other values. In the next section, we shall turn to this challenge and provide some reason to dismiss it. ${ }^{8}$

\footnotetext{
7 This distinction is clearly introduced and at work in Frankena (1973, p.84), Moore and Crisp (1996, p.599) Crisp (2006, pp.102-103); and Fletcher (2013, p.206). Griffin (1986, pp.31-34) and Sumner (1996, pp.16-17) present a closely connected distinction. See Brülde (2007a) for a review of the various types of common subdivisions of theories of well-being.

${ }^{8}$ Scanlon (1998, pp.126-141) has formulated another powerful sceptical challenge to the effect that wellbeing is not as important in first-personal thinking as often alleged. See Rodogno (2008) for a reply.
} 


\subsection{Scepticism about well-being}

In 1903 G.E. Moore challenged the idea that something can be 'good for' someone, if this notion is to be understood as a value independent of what Moore calls absolute goodness (see also Rabinowicz and Rønnow-Rasmussen, this volume). He asks:

In what sense can a thing be good for me? It is obvious, if we reflect, that the only thing which can belong to me, which can be mine, is something which is good, and not the fact that it is good. When therefore, I talk of anything I get as 'my own good,' I must mean either that the thing I get is good, or that my possessing it is good. (1993, sec. 59)

The notion of 'my own good' strikes Moore as strangely proprietary and, as he goes on to argue, its proprietary nature has unwelcome effects on its normativity. Hurka (1987) and Rosati (2008) have glossed Moore's point by drawing a parallel between the expressions 'good for me' and 'true for me'. As Rosati $(2008,314)$ puts it:

Just as the latter expression suggests a kind of truth that the individual herself could have exclusive reason to believe, so the former expression suggests a kind of value that the individual herself could have exclusive reason to promote, and that, Moore evidently thought, would be no kind of value at all.

The problem, as Moore sees it, is that goodness, just like truth, cannot be relativized in the proprietary way suggested by the expression "good for". Goodness can only be absolute. Therefore

... the only reason I can have for aiming at 'my own good' is that it is good absolutely that what I so call should belong to me. ... But if it is good absolutely that I should have it, then everyone else has as much reason for aiming at my having it, as I have myself. (1993, sec 59)

If correct, this view spells trouble for the notion of well-being or good for. As Rosati notes (2008, p.315), the challenge at hand here is ultimately metaphysical. If Moore is right, the idea of a person's 'own good' signifies nothing over and above the idea that the thing a person gets is good or that the state of her possessing it is good or, the idea of good occurring in a person's life (Regan 2004). There is, in other words, no distinctive normative property beside that of goodness, in conjunction with the fact that it occurs in someone's life. It would be an error to postulate the existence of a property such as being good for $P$.

In the eyes of those who defend the irreducibility of well-being, however, the Moorean proposal misses the point. It is not enough, they will say, that something of value occurs in a subject's life in order for her to be benefitted by it. It may well be that all sorts of good things occur in her life but, as it happens, she is continuously asleep or unconscious, or that she finds these good things uninteresting, meaningless, or even alienating. How would she benefit from these occurrences? The problem is that on the Moorean analysis the goodness of those things that are supposed to benefit a subject is determined in the absence of any reference to features of the subject or class of subjects for which these things are supposed to be good.

Note that reference to the subject here is not necessarily to be understood as a reference to a particular individual with a specific (to her) conative and/or affective profile, but rather more generally, as a member of a community characterized by community-specific biological and psychological features. At this stage, then, the point against the Moorean is not made from a subjectivist stance. It is rather an invitation to consider analyses of 'good for' that articulate this 
concept in terms of what is suitable or fitting to a certain class of subjects. Suitability and fittingness are relational notions: something is fitting or suitable always to someone or something. On the analysis sketched here, then, well-being is a relational good.

The fundamental idea of the analysis is nicely captured by Railton (1986a, p.9) who takes relational goodness to have

a place in the scheme of things only in virtue of facts about what matters, or could matter, to beings for whom it is possible that something matter. [It] would have no place within a universe consisting only of stones, for nothing matters to stones. Introduce some people, and you will have introduced the possibility of [relational] value as well. It will matter to people how things go in their rock-strewn world. Of course, what in particular will matter, or could matter, to these people will depend upon what they are like.

The idea of fittingness or suitability at issue here ought to be qualified in two important ways. First, as mentioned above, relationalism does not entail subjectivism. While reference to a group characterized by some distinctive (biological, psychological, etc.) features is essential, the reference need not track the pro-attitudes of the single individual. Relationalism is hence compatible with objective theories of well-being. ${ }^{9}$ Whether such theories can capture the particular individual's perspective or stance sufficiently well is, of course, another matter.

Secondly, relationalism abandons the Moorean idea of an absolute, monadic goodness property, which is then relativized to an individual in order to account for his good. Rather, we are from the start dealing with a distinct, relational value property. ${ }^{10}$ The upshot is that we are no longer prompted as were the Mooreans to interpret " $\mathrm{X}$ is good for $\mathrm{P}$ " as necessarily involving agentrelativity.

In short, the claim that well-being is a relational good is, as such, a modest or unassuming claim to be contrasted with absolutist approaches to value such as Moore's. In particular, while it leaves room for analyses that define well-being as subjective and/or agent-relative, it does not exclude objective and agent-neutral accounts as well as mentalist and non-mentalist accounts. Relationalism should be seen as a first step of any sui generis analysis of well-being understood as a kind of value resistant to the reductive challenge put by Moorean sceptics. With the exception of some versions of the Objective List theory, all of the theories of well-being discussed below can and should be seen as theories of relational well-being.

\subsection{Theories of well-being}

\subsubsection{Hedonism}

At the substantive level, hedonism is understood as the claim that pleasure is the only prudential value and pain the only prudential disvalue. At the formal level, hedonism consists in the claim that

\footnotetext{
${ }^{9}$ Aristotelian eudaimonia should be understood as relational in the sense I have in mind without being subjectivist (see Kraut 2007). The relevant relata are individuals qua human beings, and not qua particulars with individualized conative profiles.

${ }^{10}$ We should understand "X is good for $\mathrm{P}$ " not as taking the logical form ( $X$ is good) for $P$ but rather $x G p$, where ' $G$ ' expresses the relation is good for between relata $x$ and $p$ (Rosati 2008, 329, note 43).
} 
pleasantness and painfulness are respectively the only prudential value- and disvalue-makers. Traditionally, when referring to hedonism, one conjointly refers to, both, the formal and substantive claims (e.g. pleasurable states are the only prudential goods because pleasantness is the only prudential value-maker). Hedonists go on to claim that well-being is the greatest positive balance of pleasure over pain.

The philosophical fortunes of hedonism have tended to wax and wane through the ages. ${ }^{11}$ In the $19^{\text {th }}$ and $20^{\text {th }}$ century, it came more prominently to the foreground through the work of Jeremy Bentham (1789) and, in different forms, the other famous classical Utilitarian thinkers, J.S. Mill (1861) and Henry Sidgwick (1907). Note that at least in Bentham and Mill, well-being is equated to happiness, where the latter is understood hedonistically in terms of pleasure and the absence of pain. As we shall see, however, both, the equation of happiness and well-being and the hedonistic analysis of happiness have been contested in the recent debate. While in the latter part of the $20^{\text {th }}$ century hedonism was thought to have received a fatal blow at the hands of Nozick (1974), its prospects seem rosier today through some revived efforts in both philosophy (Crisp 2006; Feldman 2004) and psychology (Kahnemann, 1999).

In order to assess the plausibility of hedonism as a prudential theory, one should first understand the way in which the central notions of pleasure and pain are understood. There are at least two models or conceptions. On the sensation model, operative in Bentham, pleasure and pain are sui generis sensations, readily discriminable in our experience from other sensory perceptions and from each other, and susceptible of no definitions other than ostensive ones (Sumner 1996, p.88). Bentham (1789, Ch.5) thought of pleasure as embracing experiences such as bodily pleasures as well as all forms of gratification, enjoyment, satisfaction, fulfilment, etc. What these experiences all have in common is their positive tone: "an intrinsic, unanalyzable quality of pleasantness which is present to a greater or lesser degree in all of them." (Sumner 1996, p.88) On the sensation model, then, pleasurable and painful experiences are homogenous or uniform in their quality, and heterogeneous in their sources or causes. In fact, more specifically, pleasurable (and painful) experiences are uniform in quality, while varying in intensity, duration, and their causes.

The attitude model acknowledges that pleasurable and painful experiences may be quite heterogeneous and thus cannot be placed under the label pleasure and pain simply on the basis of their phenomenal character. This is rather to be done by taking into account the attitudes that accompany such sensations as, for example, our liking, seeking, or wanting these experiences to continue or our disliking, avoiding, or wanting these experiences to cease.

Let us now assess hedonism as based, in turn, on the sensation and on the attitude models of pleasure. The first criticism against sensation hedonism is that it fails properly to reflect the structure of our prudential choices. Griffin $(1986$, p.8) may be taken to make this point through the example of Freud who, at the very end of his life, ill and in pain, refused drugs except aspirin, claiming to prefer thinking in torment to not being able to think clearly. Griffin argues that we cannot find a single pleasurable feeling or mental state in both of Freud's options in virtue of which he ranked them as he did. The hedonist would have to reply that Freud was making an evaluative mistake.

A second criticism may be put forth by those with subjectivist leanings (Sumner 1996, p.93). On the sensation model, pleasurable experiences are to determine an individual's well-being irrespective of the way in which the individual relates to them, even after reflection. On this model, whether a subject actually desires or endorses his pleasurable experiences is irrelevant to the prudential

${ }^{11}$ See Plato (360 BCE; 380 BCE) for early discussions. 
value of his life (or only relevant to the extent to which failing to desire or endorse these experiences is itself unpleasant).

The third and final criticism comes across through another classic example (Crisp 1997, pp.24-25). Consider two lives: that of a brilliant musician who composed wonderful music, influenced the evolution of the symphony, was met with success and honour in his own lifetime, was cheerful and popular, travelled and gained much enjoyment from field sports but died at the age of seventyseven; or the eternal life of an oyster which enjoyed only mild sensual pleasure rather like that experienced by a human when floating very drunk in a warm bath. Now if pleasure is homogenous and is to be measured only in accordance to its intensity and duration, even granting that the first life involves more intense pleasures, the oyster's life will in the end have lasted long enough to have accumulated a greater quantity of pleasure. That, then, should be the option we should prudentially prefer on this type of hedonism. Many, however, would judge the musician's life better in welfare terms, no matter how long the oyster's life.

One could at this point argue along with J.S. Mill (1861) that pleasures are heterogeneous and that some 'higher' pleasures are more valuable than 'lower' ones, no matter the amount of the latter. This move would clearly solve cases such as the musician's: his life will always be better for him than an oyster's life, no matter how extended a life. The question, however, is whether the move is open to sensation hedonists or, for that matter, to hedonists in general. A position such as Mill's seems to face a dilemma: either return to a homogenous view of pleasure where pleasurable experiences are to be compared only in terms of their intensity and duration, or renounce sensation hedonism.

To see this point, consider two pleasurable experiences, a 'higher' and a 'lower' one. On the one hand, if pleasantness were the only prudential value-maker, it is hard to see how increasing the intensity or duration of the 'lower' experience would not at some point generate enough pleasure as that contained by the 'higher' experience. In this instance, no case can be made for the discontinuity in pleasurable experiences imagined by Mill, and hence the distinction between 'lower' and 'higher' pleasures would fall. On the other hand, if the two experiences were not to be commensurable in this way, then what makes higher 'pleasures' more valuable must be something other than their pleasantness. ${ }^{12}$

In order to preserve hedonism, while at the same time providing an answer to the musician's case, some have moved to attitude hedonism, ${ }^{13}$ which easily allows discontinuities in our attitudes towards various experiences such that, for example, we would always enjoy something more than something else we also enjoy, no matter the amount of the latter. Attitude hedonism would also clearly be more palatable to those who favour subjectivist views of well-being.

Desires have historically occupied an important role as the relevant pleasure-defining attitudes within Attitude Hedonism. ${ }^{14}$ Mill (1861, IV10), for example, writes that "to desire anything, except in proportion as the idea of it as peasant, is a physical and metaphysical impossibility." This claim, however, seems false as Nozick (1974, pp.42-43) argues through his famous thought experiment. Suppose you could plug into an experience machine that would give you any experience you wanted: climbing Mount Everest, saving someone's life, or being a famous actor. All the time you

\footnotetext{
${ }^{12}$ Crisp (2006) attempts to account for discontinuities while retaining the sensation model. He does this by claiming that the value of a pleasure depends on its intensity and duration as well as on its quality.

${ }^{13}$ Crisp (2006, pp.11-117) reinterprets Mill in this direction, where the relevant attitude is enjoyment.

${ }^{14} \mathrm{Katz}$ (2006) offers a nice review of other attitude theories of pleasure. Feldman (2004) is a recent good example, as pleasure is defined not simply in terms of an attitude but in terms of a propositional attitude.
} 
would be floating in a tank, with electrodes attached to your brain. Would you plug in? Nozick (1974, p. 43) wants to argue that various things matter to us in addition to pleasurable experiences. In particular, (i) we want to do certain things, rather than merely having the experience of doing them; (ii) we want to be a certain kind of person; and (iii) we want to be able to make contact with a reality deeper than one that is entirely man-made. We can call the objects of desires such as these, respectively, accomplishment, personhood, and knowledge and understanding.

Along with desires for pleasure, we do seem to have desire such as these. Perhaps, then, attitude hedonism should pick a pro-attitude other than desires, whose scope now seems too broad for substantive hedonism. What Nozick's argument allegedly brings to the fore, however, is that even if we could find a pro-attitude that successfully tracked pleasure and only pleasure, a problem would remain: accomplishment, personhood, and knowledge do seem to matter to us in a way that prudential theories should account for and substantive hedonism fails to account for that. 15

\subsubsection{Desire theories}

Theories in this group were originally developed by welfare economists with utilitarian credentials who were confronted with the resistance of pain and pleasure to reliable, public measurement. ${ }^{16}$ Desire theories owe their current dominance in large part to the emergence of welfare economics.

Philosophically, we should see desire theories mainly as formal theories stating, in their simplest form, that what makes someone better off is the extent that their current desires are fulfilled. On such present desire theory, substantively, an individual's well-being consists in the obtaining of the objects of her current desires, whatever they may be. ${ }^{17}$ In philosophy, however, this view is not very popular, as it is open to one simple objection: we do happen to desire or prefer things that are clearly not in our interest or good for us and, in fact, things that are positively bad for us. ${ }^{18}$

In the contemporary debate, the type of desire theory that has by far drawn the largest amount of support goes under a number of different appellations, to wit, informed desire, full information, or ideal preference accounts of well-being. Spurred by early and incisive efforts made by Henry Sidgwick (1907: 111-112), the account comes today in various shades (Griffin, 1986, chs. 1-2; Harsany 1982; Brandt, 1979, chs. 6-7; Rawls, 1971, 417 ff). The common idea behind them all is that well-being is to be characterised by starting with a desire (or with a preference or with contentment) that is idealized by attaching some condition $\mathrm{C}$, be it avoidance of the influence of mistaken belief and of ignorance of material facts, etc. ${ }^{19}$ One example would be the following:

\footnotetext{
${ }^{15}$ Crisp (2006, pp.117-125) argues that substantive hedonism can account for the prudential value of these things in an indirect way.

${ }^{16}$ See Little (1950) for the evolution of modern utility theory at the hands of economists and Sumner (1996, pp.113-122) for a very short introduction to revealed preference theory that connects it to its classical utilitarian roots.

${ }_{17}$ Note, however, that there may logically be substantive versions of desire theories according to which what has final prudential value is the circumstance that an (intrinsic) desire is satisfied (as opposed to the states that are the objects of our desire) (Brülde 2007a, p.7).

18 See Parfit (1984, pp.496-499) for summative and global versions of desire theories (where the former claim that the more desire-fulfilment in a life the better, and the latter claim that desires about the shape and content of a part or of the entirety of one's life are given priority).

${ }^{19}$ Brandt for example defines as rational the intrinsic desires that would survive the idealised scrutiny that he describes under the notion of 'cognitive psychotherapy': an intrinsic desire is rational if a person would still
} 
$g$ is an ingredient of $x^{\prime}$ s well-being if and only if $g$ is what $x$ would desire if $x$ 's rationality could not be faulted and $x$ was equipped with all relevant information.

Robert Shope (1978a; 1978b) subjected these account to an objection known as the conditional fallacy: idealization, he claimed, may well lead to fairly counterintuitive and arbitrary results. Suppose that something is good just in case an agent would choose it, if she were fully deliberatively rational. Suppose now that a troubled person is considering whether to go to psychotherapy. Now if this person were fully rational she would not choose to go to psychotherapy, for, as someone who is fully rational, she would not need to. But on the account at hand, this means that it would not be good for the troubled person in the actual world to go to psychotherapy. ${ }^{20}$

To avoid this kind of objection, Railton (1986a, 1986b) has developed another, more sophisticated version of the informed desire account:

[A]n individual's good consists in what he would want himself to want, or to pursue, were he to contemplate his present situation from a standpoint fully and vividly informed about himself and his circumstances, and entirely free of cognitive error or lapses of instrumental rationality. (1986a: 16)

This type of analysis is often referred to as an ideal advisor account of an individual's good, as the latter is defined in terms of what a cognitively idealized version of the self would advise the actual self to want and pursue.

Informed desire or ideal advisor kinds of account have also received other criticisms. Perhaps the most fundamental one comes from those who find them too subjective. Rawls (1971, p.432) gives a good illustration of the tension at play here through a famous example: a brilliant mathematician, fully informed about the options available to her, develops a desire to spend much of her life counting blades of grass. Thoroughgoing subjectivists will accept that if she really is informed and not suffering from some psychic condition, then the life of grass-counting will be best for her. Others will find this conclusion too unpalatable.

Yet other criticisms appeal to one or more of the following issues: (i) the incoherency of the notion of a fully informed agent; 21 (ii) the failure of such accounts to account for the autonomous features of agency (Rosati 2000); (iii) their lack of normative force; and (iv) their susceptibility to the scope problem. Two important criticisms are worth mentioning here.

The first covers points (i) and (iii). If a person is to appreciate information, argues Rosati (1995), she must be capable of receiving it. What kind of information a given individual takes as informing (can receive) is a function of this individual's personality at a time, it is a function of who she is at that time. Given an individual's personality, some information is such that the individual would have to change her personality quite dramatically in order to be able to receive it. To illustrate: if the extremely cautious individual wants to know whether it would be good for her to become an adventurous person, she should not appreciate adventurous lives only from the perspective of her actual cautious self, but also from the perspective of more adventurous selves.

have it after repeated representation of all relevant scientifically available information, in an ideally vivid way, at appropriate times.

${ }^{20}$ Hubin (1966) and Gibbard (1990, p.20) have further developed this type of objection.

21 Velleman 1988; Sobel 1994; and Rosati 1995. For replies see Miller 2003, pp.208-217; and Zimmerman 2003. 
At the end of the process of imaginatively surveying her possible lives in all their permutations, she must have... traits that enable her to appreciate what each experience was like, rather than traits that enable her to appreciate only some experiences while not appreciating others. Even if we assume that we are still imagining a person at the end of this process, it is surely a person radically different from (albeit continuous with) the person who underwent idealization. (1995: 319)

This difference, however, results in a failure of identification between the person who occupies the ideal standpoint and the person who is being idealized, which in turn results in the latter failing to take the responses of the former as authoritative and motivating.

The final criticism covers the so called scope problem. As discussed in Section 1, the limits of the concept of well-being are drawn with the help of the concept of self-sacrifice. An account that classifies under the idea of well-being states or actions that are clearly self-sacrificial has too wide a scope. Many (Darwall 2002, pp.25-31; Griffin 1986: 16-17; Sumner 1996: 124-128) believe desire accounts to be susceptible to this problem. The problem is so acute that it can be spotted even without an appeal to self-sacrifice. As Scanlon (1998, p.115) puts it:

...the objects of a person's informed desires are likely to include many things that are not related to the quality of the desirer's own life, intuitively understood. Suppose, for example, that I very much admire a certain person, and therefore desire that her struggle and sacrifice will be crowned with success and happiness. This may be a rational desire as well as an informed one; it might, quite properly, be strengthened by fuller knowledge of the person's life and character. Even if this is so, however, if I have no connection with her beyond my admiration and this desire, then the quality of my life is not affected one way or the other by her fate. ${ }^{22}$

Some informed desire theorists accept that the type of account they defend has too wide a scope. They therefore adopt a strategy that consists in restricting the scope by selecting only those desires that pertain to the subject's own life. Overvold (1982, p.90), for one, proposes an account in terms of only those desires whose object includes states of affairs the obtaining of which requires the existence of the subject. ${ }^{23}$ Consider Scanlon's example above. My desire that the person reaches success does not at all fulfil this requirement, for it is not logically required that I exist in order for the admired person to reach success. Overvold would agree with Scanlon, then, that the satisfaction of this desire would not count towards a person's well-being and his account would have a principled way of showing why this is so.

Overvold's analysis, however, is still too restrictive in some respects and not restrictive enough in others. The latter is the case insofar as, for example, the analysis allows me to have an informed desire to do my duty that requires my existence but that is clearly not to my advantage. Yet, the account seems too restrictive insofar as it excludes informed desires the fulfilment of which does not necessarily entail my existence but which are potentially good for me such as, for example, my desire that one of my projects, e.g., saving Venice, succeeds after my death.

Finally, other (individual or cumulative) strategies would consist (i) in expanding the idea of a person's good as idealists have suggested (Skorupski 2006); (ii) in discussing more substantive and affective accounts of the notion of desire (De Sousa 1987, pp.167-69; Skorupski 1999, pp.130-133);

\footnotetext{
${ }^{22}$ Scanlon elaborates here a point and an example originally made by Parfit (1984, p.494). See also Kagan (1998, p.37)

${ }^{23}$ Griffin (1986, pp.21-23) offers another account that acknowledges the scope problem while attempting to address it by restricting the scope.
} 
or (iii) in attempting to deflate the problematic nature of the scope "problem" by showing that wellbeing and self-sacrifice do not stand in a straightforward exclusionary relation (Raz 2000; Rosati 2009b).

\subsubsection{Happiness Theories}

What we call here Happiness Theories are fairly recent additions to theories of well-being, with only two major exponents or theories, namely, Haybron's (2008) Psychic Flourishing and Sumner's (1996) Authentic Happiness. Both accounts consist of two parts: first, a psychological account of happiness and, second, a specification of the role of happiness within a theory of well-being. At the psychological level, both theories react to the Classical Utilitarian hedonic understanding of happiness, yet propose rather different views of happiness as alternatives. At the level of their theories of well-being, both accounts allot happiness a central role (hence their denomination as Happiness Theories). Yet, while on one account happiness is considered as a central substantive good (Haybron 2008) on the other it is the sole formal good or prudential value-maker (Sumner 1996). Let us say a few more words about each account, beginning with Sumner's Authentic Happiness. ${ }^{24}$

On this view, psychologically, happiness is understood as a disposition involving both a cognitive and an affective component:

The cognitive aspect of happiness consists in a positive evaluation of the conditions of your life, a judgement that, at least on balance, it measures up favourably against your standards or expectations. ... It represents an affirmation or endorsement of (some or all of) the conditions or circumstances of your life, a judgement that, on balance and taking everything into account, your life is going well for you. ... However, there is more involved in being happy than being disposed to think that your life is going (or has gone) well. The affective side of happiness consists in what we commonly call a sense of well-being: finding your life enriching or rewarding, or feeling satisfied or fulfilled by it. (Sumner 1996: 146-147)

From a psychological perspective, then, happiness is a retrospective evaluative attitude or disposition with, both, a cognitive and an affective component. Let us call this view of happiness Life Satisfaction as this idea captures, both, the evaluative idea that one's life satisfies one's goals, and the more hedonic idea of one's sense of satisfaction, gratification and the like.

What role does happiness so understood play in this theory of well-being? As characterized so far, happiness cannot yet play its role as prudential value-maker because a person's happiness may either rest on a mistake, as when, for example, the person is misinformed about the facts, or be less than fully autonomous, as when, for example, the person's life experiences have affected her ability to reflect critically on her situation. Sumner therefore introduces the notion of Authentic Happiness as a shortcut for 'factually informed and autonomous happiness'. With this notion in hand, Sumner (1996, pp.172-173) introduces his theory of well-being:

${ }^{24}$ See Brülde (2007b) for a systematic and in depth review of happiness theories as well as a defence of another version of them. 
[S] ome condition of a subject's life is (directly or intrinsically) beneficial for him just in case he authentically endorses it, or experiences it as satisfying, for its own sake. The intrinsic sources of welfare will be whatever conditions of subjects' lives elicit this response.

The authentic happiness view looks very much like a formal, informed desire theory of well-being, with authentic happiness playing a role analogous to informed desire. Like informed desire views, the happiness view is supposed to be thoroughly subjective: nothing can count as beneficial for someone unless the subject has or is disposed to have the relevant attitude. As in informed desire theories, the level of subjectivity may be too much for some. Hence, for example, on this theory "one cannot assume a priori that the happy slave has a bad life, or that a life of servility and subservience (a life which we regard as trivial or demeaning or depraved) cannot be prudentially valuable for its subject." (Brülde 2007b, p.44) As Sumner (1996, p.182) would retort, however, we can have pretty good empirical reasons for thinking that such a life is rarely embraced under conditions of full autonomy, and therefore not likely to be a good life.

Similarly, those who believe that informed desires view have a scope problem should also harbour a similar worry with regard to the authentic happiness view. Even though (authentic) happiness is supposed to be elicited in connection with standards that apply to the subject's own life, the standards in question may well refer to projects, such as saving Venice or eradicating poverty, the accomplishment of which may work against an intuitive understanding of the subject's well-being.

A connected worry with scope arises when we look at the way in which people answer questions concerning how happy or satisfied they are with their life. As Haybron (2008, p.92) puts it:

Life satisfaction attitudes are governed by norms that make systematic, often radical, deviations from well-being-by any sane measure-both expectable and utterly reasonable. You might, for instance, be satisfied with your life, not because you think things are going well for you, but because that seems to you the most fitting or appropriate way to respond to the life you have.

Hence someone in a predicament may still express satisfaction with life, if her attitudes embody norms such as gratitude, fortitude, ambition, pride and the like.

Finally, there are also worries with regard to Sumner's psychological view of happiness. In a sustained critique of this view, Haybron (2009, pp.79-103) argues among others that this attitude is not psychologically robust. Part of the argument turns around the alleged cognitive and affective nature of Life Satisfaction. Now this view would be put under some strain by findings that confirm cognitive-affective divergence, i.e., cases in which a person displays, say, the cognitive element of the happiness evaluation without displaying the affective element. And sure enough there is solid evidence to that effect (Haybron 2009, pp.84-86).

Let us now move on to Haybron's substantive happiness account (2008, pp.105-151). This view rests on quite a different psychological account of happiness. Instead of identifying happiness with pleasurable experience, as in Classical Utilitarianism, or with Life Satisfaction as Sumner's does, happiness here consists in a subject's emotional condition as a whole. This includes nonexperiential aspects of emotions and moods (or perhaps just moods), and excludes pleasures that don't directly involve the individual's emotional state. It might also include a person's propensity for experiencing various moods, which can vary over time. Happiness on such view is more nearly the opposite of depression or anxiety, whereas hedonistic happiness is simply opposed to unpleasantness. Finally, on Haybron's view, emotional state happiness involves three broad categories of affective state, including "endorsement" states like joy versus sadness, "engagement" 
states like flow or a sense of vitality, and "attunement" states like tranquillity, emotional expansiveness versus compression, and confidence. Haybron calls this view psychic flourishing.

Haybron argues that happiness understood in this sense plays a central substantive role in a theory of well-being. A theory of well-being such as this can only be fully assessed when one also knows what other goods the theory includes and what importance such goods have relative to happiness and to each other. This point notwithstanding, another fundamental challenge stands in the way of any theory of well-being that takes happiness to be a central, substantive good. Some may fail to be swayed by the claim that psychic happiness is a final prudential good and a central one at that. Just as many would be inclined to think that depression and anxiety, the opposite of happiness on Haybron's account, are reliable indicators that a person is doing bad, being in the positive emotional state described by Haybron may be taken as an indicator that we are doing well. The suggestion here is analogous to one made by many psychologists and philosophers of emotion: just as emotions serve the evaluative function of indicating how we are faring in our environment, the affective states that constitute psychic flourishing serve the evaluative function of indicating whether our lives contain those things that, themselves, are ultimately good for us (Rodogno In Press).

\subsubsection{Objective List and Perfectionist Theories}

Like hedonism, objective list theories can be understood either as substantive, or as, both, formal and substantive theories of well-being. In either case, the substantive claim these theories make is that there is an irreducible plurality, a list, of prudential goods such as pleasure and the absence of pain, achievement, friendship and other deep personal relations, autonomy, virtue, knowledge, etc. This is a feature of these views traditionally asserted contra hedonism, which, as we saw, is a substantively monistic view. The list, however, is also supposed to be an objective one. This is a formal feature generally common to this family of theories to the effect that the subject's proattitudes are not necessary prudential value-makers. ${ }^{25}$ In this respect, objective list theories are unlike desire theories or Authentic Happiness.

There is, however, disagreement with regard to what other formal claims are true of objective list theories. One possible position reflects the structure of classical hedonism quite closely. Just as for the latter there is one substantive good, i.e., pleasurable experience, and one value-maker, i.e., pleasantness, objective list theorists would claim that there is a plurality of substantive goods each accompanied by its respective value-maker. This is a commitment incurred by philosophers such as John Finnis (2011) who provides a list of basic human goods (life, knowledge, play, aesthetic experience, friendship, practical reasonableness, and religion), that are (i) basic aspects of one's well-being and final ends; (ii) known by practical reason (or self-evident); and (iii) not grounded in any metaphysics or anthropology (Finnis 1983, 22).

Another possibility, however, is that one finds unity at the formal level precisely via an appeal to metaphysics or anthropology. This, for example, is the aim of perfectionist theories, according to which what makes something a component of well-being (an entry on the substantive list) is their

25 "Generally" because, as we shall see below, some theories within this family may indeed claim that some, if not all, the goods they list necessarily involve some pro-attitude. We shall discuss the objectivist credentials of such theories below. 
role in perfecting human nature. Aristotle, for example, famously thought that human nature has a specific telos or function and that whatever activity contributed to developing or perfecting this function would by necessity be part of one's well-being. ${ }^{26}$ Not all varieties of perfectionism, however, are, as Aristotle's, grounded on human nature. According to Haybron (2008, pp.177-196), for example, we should perfect or fulfil the self, and, in particular, what he calls the emotional self.

One objection posed to objective list views such as Finnis' is that they are based on a number of unsystematic intuitions. Reliance on intuitions, however, is not uncommon to this area of philosophy. Hedonism does after all rely on intuitions about pleasurable experience and pleasantness. Arguably, one could similarly take perfectionism to rely on the intuition that whatever fulfills one's nature is of prudential value. ${ }^{27}$

Consider now perfectionist versions of the objective list theory. One objection often posed to them denies as conceptually confused their fundamental intuition: perfectionism mistakes prudential value for perfectionist value (Glassen 1957, p.320). Consider our Harvard grass-counting mathematician once again. Suppose that exercising and perfecting her mathematical skills would have perfectionist value, would make her a more perfect exemplar of her kind. Why think at the same time that this would be prudentially better than any option, such as counting grass all day, that did not develop her human nature as much? As Sumner (1996, p.24) puts it: "there is no logical guarantee that the most developed specimen will also be the best off, or that their undeveloped rivals would not be faring better." Then again, perfectionists may well agree that perfectionist and prudential values are conceptually distinct while at the same time making the claim that they are substantively overlapping in some cases.

Finally, the most fundamental objection to objective list theories (in any guise) is inspired precisely by their alleged objective nature, i.e., that a prudential good may be what it is irrespective of the subject's pro-attitudes towards it. As Railton (1986a, p.47) writes:

It would be an intolerably alienated conception of someone's good to imagine that it might fail in any way to engage him.

A possible line of reply consists in accepting the charge while refusing that all lists of goods need be alienating. Fletcher (2013, pp.215-216), for example, endorses a list comprising of goods that have pro-attitudes as necessary components. Hence goods such achievement, friendship, happiness, pleasure, self- respect, and virtue would allegedly involve the person's engagement through her holding various kinds of pro-attitudes such as endorsement, desires and affection. If one is experiencing these kinds of states of engagement, one is doing well. On this view, however, it looks like the pro-attitudes at issue are internal or constitutive of the various goods at hand rather than pro-attitudes about them. Now, we can all agree that friendship involves the pro-attitudes of desiring to spend time and engaging with one's friend. What's crucial to respond to the alienation charge, however, is whether one should have a pro-attitude towards friendship relations (and the pro-attitudes they involve). Suppose an individual lacked such pro-attitude. Would friendship be on her list of goods anyways? If so, the view proposed here does not answer the alienation challenge.

\footnotetext{
${ }^{26}$ See Hurka (1993) for a contemporary version of perfectionism. Note, however, that like Moore (1903), Hurka is sceptical about prudential value and hence his perfectionism is intended as a full-fledged moral theory: the good life is that which develops human nature and the development of human nature is ultimately (as opposed to merely prudentially) good.

27 Dorsey (2010) argues that all other kinds of arguments in favour of perfectionism, i.e., Hurka's (1993) essence argument and Brink's (2007) agency argument, ultimately rest on this intuition, which, he argues cannot support perfectionism on its own.
} 
Another line of reply is to read objective list views such as Hursthouse (1997) and Nussbaum $(2000$, p.78, 160) as involving the requirement that each of the goods on the list be thought important by the actual subjects. ${ }^{28}$ Far from being an objective list theory, however, this would be a subjective theory, where the subject's relevant pro-attitude is thinking that thing important as opposed to, say, desiring it.

\section{Well-Being in Psychology}

Work on the psychology of happiness and well-being seems largely unconcerned with the formal and substantive theories that entice philosophers and more concerned with operationalizing and measuring some conception or other of happiness or well-being and, more importantly, with uncovering the correlations and causal relations that stand between the view of well-being at hand and various activities and state of affairs (being married, being unemployed, level of income, physical and mental health, etc.). Overviews of the recent psychological literature (Tiberius 2006, 2007) suggest that researchers in this field work with three conceptions of happiness and/or wellbeing: Objective Happiness, Subjective Well-being, and Eudaimonism. Below, I shall follow this categorization and present these conceptions in turn. The focus will be on relating them to their respective philosophical counterparts and, by so doing, on bringing philosophical thinking to bear on psychological research. ${ }^{29}$

\subsection{Objective Happiness}

Objective Happiness is the name that Kahneman (1999) has chosen for the approach he and his affiliates have developed. The approach is thoroughly Benthamian in at least three ways: (i) psychologically, happiness is here understood in hedonistic terms as pleasure and the absence of pain (as opposed to psychic flourishing or life satisfaction); (ii) prudentially, substantive hedonism is also taken to be the case, i.e., pleasure is the only value and pain the only disvalue; and, finally, (iii) pleasure is to be understood as on the sensation model: i.e. pleasurable experiences are homogenous, varying only in their intensity and duration. ${ }^{30}$

The idea of objectivity in Objective Happiness is largely in line with that discussed above, as it involves a denial of the subject's pro-attitudes in the determination of his or her well-being. To be more precise, objective happiness denies a role to retrospective evaluations of one's experiences and life such as those constituting life satisfaction. The reasons for this denial are both ontological and methodological. Ontologically, as we saw, happiness amounts to the positive balance of pleasure over pain, which, in this context, involves the integrated durations and intensities of all pleasures minus the integrated durations and intensities of all pains. Now as a number of experiments have

\footnotetext{
28 Tiberius (2007, pp.380-81) suggests this reading of Nussbaum and Hursthouse.

${ }^{29}$ I shall avoid focussing on the substantive results, i.e., the correlations and causal relations, uncovered by research conducted within each paradigm. The interested reader will find it useful to read Kahneman and Krueger (2006); Diener and Seligman (2004); and Ryan, Huta, \& Deci (2008).

30 These claims are for the most part based on Kahnemann (1999). See also the other contributions in Kahneman et al. (1999).
} 
shown (Kahneman 1999), retrospective evaluations of one's experiences introduce all sorts of biases in our evaluations of pleasures and pains. They are, therefore, methodologically or epistemologically, the wrong kind of tool for the measurement of (objective) happiness. It is for this reason that Kahneman (1999) proposes a bottom-up methodology aimed at constructing measures of happiness that aggregate moment-by-moment measurements and that avoid reliance on retrospective evaluations. The whole argument, however, is grounded in the undefended assumption that Objective Happiness involves the right views of, both, happiness and well-being. Without this premise the idea that retrospective evaluations introduce biases is entirely unsupported. As we saw in Section 2, however, hedonism does have its critics.

Specific versions of these criticisms can be observed in the way in which Kahneman and affiliates operationalize happiness. Remember, for example, the exchange between quantitative and qualitative hedonists discussed above, the latter endorsing heterogeneity in the quality of pleasure, the former, like Kahneman, denying it. In fact, on a closer reading, Kahneman may seem less firm on this point than previously stated, as he does also claim (1999, pp.6-7) that beside the hedonic quality of current sensory experience, his notion of instant utility should include the pleasures and pains associated with anticipation of future experience and with remembering the past; other pleasures of the mind such as states of "flow" in which one is so involved in an experience or activity where hedonic value fades into the background of experience; mood; activities that have a promotion focus or a prevention focus, and situations that vary in the extent of personal control. The question, here, is whether we can call in the appropriate hedonic sense "pleasures of the mind" experiences for which "the hedonic value fades into the background" and similarly with activities with a promotion as opposed to an aversion focus, or situations that vary in the extent of personal control.

Granting that all these items are indeed hedonic in the relevant sense, Kahneman faces an important operationalization challenge. As he is well aware $(1999$, p.7), it may be an intractable task to measure all these items on the same bipolar scale with a zero point at the centre, displeasure at one end, and pleasure at the other, what he calls the Good/Bad scale. He also claims, however, that the study of objective happiness can be pursued usefully on such a scale with much weaker measurements of instant utility, as it is not particularly difficult to distinguish good, bad, and neutral moments. As "a first approximation", he writes, we could call someone objectively happy if, during a set period of time, she spent most of her time engaged in activities "that she would rather have continued than stopped, little time in situations she wished to escape, and -very important because life is short-not too much time in a neutral state in which she would not care either way." (Kahneman 1999, p.7)

In short, desires and aversions for specific activities and experiences are to measure instant utility. Perhaps they do in some sense of "utility". The question, however, is once again whether this appeal to desires and aversions maintains a strong enough connection to utility understood hedonically. Pace Mill (1998, 85, IV10), it is not clear that there is a one-to-one physical (and a fortiori conceptual or metaphysical) connection between desire and pleasure, on the one hand, and aversion and pain, on the other. ${ }^{31}$ We may, in other words, desire things in virtue of properties other than their pleasantness. If this is true, there would be little reason to believe that the Good/Bad scale is a hedonic scale and, hence, that it is a unitary bipolar scale.

Friends of Objective Happiness seem to be undeterred by such worries thinking perhaps that, all in all, desire and approach behaviour is robustly connected to pleasure and aversion and avoidance

\footnotetext{
${ }^{31}$ Simplifying very much, the work of neuroscientist Berridge (2009) shows that while hedonic "liking" is
} often connected to what he calls "wanting", the latter is not as likely to be connected with the former. 
behaviour to pain. Even if one granted this much, however, there is reason to be sceptical with regard to the idea that hedonic tone is a consistent feature of the affective realm measurable on a bipolar scale. If positive and negative affective states are to be a sound measure rod, their actual occurrences qua groups should be inversely correlated, for if they weren't the occurrence of, say, a negative state may well be accompanied by the occurrence of a positive state. And if that were the case, it would be meaningless to measure well-being by subtracting occurrences of negative emotions from occurrences of positive ones, for a negative emotion may well tend to be accompanied by a positive one. Yet, various correlation studies (de Boer 2013, pp.9-12) show that the negative correlation between positive affect and negative affect is invariably low, not only between subjects but also within them. These results strongly suggest that there is no bipolar scale.

Finally, we should expect opposition to Objective Happiness to arise from two of its defining features. First, from the fact that it focuses on happiness understood as the mere aggregate of many moments thus failing to take a more holistic perspective on lives. As Haybron (2008, p.83) puts it:

What matters to us, arguably, is not just having a plurality of good moments, but having a good life. And we see our lives as more than just the sum of their parts. Thus the pains suffered in boot camp, in pursuit of some other achievement, might be seen as a good thing in the context of one's life as a whole. They will at least take on a different significance from the pains considered in isolation, as mere pains. ${ }^{32}$

Secondly, resistance to Objective Happiness is likely to arise from its objectivism: what if subjects harbour retrospective negative (perhaps second-order) attitudes towards some of their moments of pleasure?

\subsection{Subjective Well-Being}

Subjective Well-Being may be conceived as an approach that affords precisely the subjectivist and holistic perspective missing in Objective Happiness. At the core of this approach is the idea that an individual's well-being is to be determined by her subjective evaluations, which comprise both cognitive judgements of satisfaction and affective appraisals of moods and emotions. More in particular:

It would be accurate to conceptualize subjective well-being as an umbrella term, consisting of a number of interrelated yet separable components, such as life satisfaction (global judgements of one's life), satisfaction with important life domains (e.g. marriage or work satisfaction), positive affect (prevalence of positive emotions and moods), and low levels of negative affect (prevalence of unpleasant emotions and moods). (Kesebir and Diener 2008, pp.66-67)

The cognitive component is typically measured with the help of self-report tools such as the Satisfaction with Life Scale, a five-item instrument that asks subjects to indicate their level of agreement on a 7-point Likert scale with the following five items:

- In most ways my life is close to my ideal.

- The conditions of my life are excellent.

- I am satisfied with my life.

- So far I have gotten the important things I want in life.

${ }^{32}$ Friends of Objective Happiness may accept this criticism, if they were allowed to refer to later pleasures. 
- If I could live my life over, I would change almost nothing.

The positive and negative affect components are measured separately as they can be somewhat independent and have different correlates. They are typically measured through retrospective selfreports though peer-informant reports and instant measures of the kind preferred by Objective Happiness theorists are occasionally used.

The Subjective Well-Being paradigm has a lot of ground in common with Sumner's (1996) Authentic Happiness theory. In both cases well-being is determined by subjective satisfaction evaluations that comprise a cognitive and an affective component. The difference resides in the fact that on Sumner's theory the evaluations have to be informed and autonomous. Given the nature of the overlap between the two approaches, the criticisms made against Sumner's theory in Section 2, should be taken to apply pari passu to Subjective Well-Being.

A couple of problems, however, are worth mentioning again here. Firstly, consider the context sensitivity of life satisfaction attitudes (Schwarz and Strack 1999) discussed in Section 2.2.4. In the eyes of critics, this feature undermines the credibility of these attitudes as attitudes that are sufficiently robust to identify well-being. Friends of Subjective Well-Being, however, see the problem differently. While they generally acknowledge context sensitivity, they seem to be more inclined to consider it as evidence of measurement problems than as evidence of a lack of the relevant stable life satisfaction disposition. That is, despite the transitory influences of moods and other distractions, subjective well-being is moderately stable across situations and across the life span (Diener and Lucas 199, pp.214). This, they claim, is also corroborated by a strong correlation between overall life satisfaction and domain satisfaction, with high test-retest stability (Schimmack and Oishi 2005).

Secondly, consider once again (Section 2.2.4) the charge that Subjective Well-being is deficient because it is too subjectivist. As claimed above, well-being is a normative (as well as a descriptive) concept. We appeal to well-being and its synonyms when, for example, (self-)criticizing an agent's choices not only as instrumentally bad but also, in some cases, as proceeding from imprudent goals and values. That is, we appeal to the agent's own well-being in order to invite her to revise her own goals and values. The problem with Subjective Well-Being is that it seems to restrict the possibility of such (self-)criticism. To illustrate this, consider the case of someone who is quite unsatisfied with her life because she has values and goals that she simply cannot fulfil. On this theory, unless the agent adopts the goal of reaching a high level of satisfaction with her life, no one can coherently make an appeal to her well-being in order to invite her to reconsider her goals and values. Yet, it is precisely out of consideration for her well-being that a friend would invite her to revise her goals and values.

\subsection{Eudaimonism}

Two of the most prominent eudaimonistic paradigms in psychology are Ryan and Deci's (2000, 2008) self-determination theory of well-being and Ryff and Singer's multidimensional account. What is common to both approaches is their opposition to conceptions of well-being focused on assessments of feeling good, contentment and life satisfaction, conceptions referred to under the heading of hedonia. Now hedonia and eudaimonia are claimed to be distinct; the latter, not the former, provides the correct basis for conceptualizing well-being. More positively, as Ryan, Huta \& Deci put it (2008, p.139), while hedonic approaches "focus on the outcome of happiness or 
pleasure", eudaimonic approaches focus "on the process of living well". Now while for Ryff and Singer (1998) living well consists in actualizing six human potentialities-autonomy, personal growth, self-acceptance, life purpose, mastery, and positive relatedness-for Ryan, Huta, and Deci (2008, p.139) it consists in (1) pursuing intrinsic goals and values for their own sake, including personal growth, relationships, community, and health, rather than extrinsic goals and values, such as wealth, fame, image, and power; (2) behaving in autonomous, volitional, or consensual ways, rather than heteronomous or controlled ways; (3) being mindful and acting with a sense of awareness; and (4) behaving in ways that satisfy basic psychological needs for competence, relatedness, and autonomy. In fact, they theorize that the first three of these aspects of eudaimonic living have their positive effects of psychological and physical wellness because they facilitate satisfaction of these basic, universal psychological needs.

Eudaimonist theories in psychology make explicit reference to Aristotelian perfectionism (Ryff and Singer 2008, pp.15-18; Ryan, Huta, \& Deci 2008, pp.142-145) and to the extent to which they do, they are open to the same kind of criticisms. The charge of alienation is perhaps the most relevant here: should I pursue friendship if such pursuit leaves me utterly cold? And what if fame, image, and power just did it for me? In fact these questions become particularly pressing when the relevant results in psychology not only inspire self-understanding and prudential self-regulation at the individual level but also influence public policy, as they increasingly seem to be doing.

\section{Conclusion}

Returning to Kim's questions, what we now can say is that these questions are in large part asked from an evaluative standpoint that is sui generis or irreducible to other evaluative standpoints. Moorean analyses that conceptualize prudential value in terms of absolute value occurring in a person's life miss an important point. They lack a relational element that is essential to the correct understanding of well-being: prudential goods are such only to the extent to which they are fitting or suitable to someone.

Relationality, however, is not to be confused with subjectivity and leaves conceptual room to objectivist theories of well-being that do not take the pro-attitudes peculiar to the individual to determine well-being. From the perspective of such objectivist theories, one could advise Kim without much in the way of reference to the conative and/or affective profile peculiar to him or her. These theories, however, will have to rely on a specific theory of human nature, or of theories of the self that give pride of place to emotional happiness, or otherwise heavily rely on some intuitions about what the human good substantively consists in. Alternatively, we may opt for a more subjectivist approach. Kim's pro-attitudes, idealised or otherwise, will at that point be an essential determinant of any answer to his or her questions.

Disagreement between subjectivist and objectivist theories of well-being is indeed a fundamental and persistent feature of the philosophy of well-being that carries over to psychological research. Another fundamental disagreement is likely to take centre stage due to the recent surge in interest in both philosophy and psychology of both psychological theories of happiness and eudaimonistic approaches to well-being. What is at issue here is whether happiness in any of its hedonic, life satisfaction, or emotional guises is formally or substantively central to well-being, or whether it is 
at best a central indicator of other states, processes, or activities that are themselves ultimate constituents of well-being. ${ }^{33}$

\section{References}

Arneson, R. (1999). Human Flourishing Versus Desire Satisfaction. In Social Philosophy and Policy, $16,113-142$.

Bentham, J. (1789). An Introduction to the Principles of Morals and Legislation, J. Burns and H.L. A. Hart (eds.) (1996). Oxford: Clarendon Press.

Berridge, K. (2009). Wanting and Liking: Observation from the Neuroscience and Psychology Laboratory. Inquiry: An Interdisciplinary Journal of Philosophy, 52, 378-398.

Brink, D.0. (2008). The Significance of Desire. In: R. Shafer-Landau (ed.) (2008). Oxford Studies in Metaethics v.3. Oxford: Oxford University Press, pp.5-46.

Brülde, B. (2007a). Happiness and the Good Life: Introduction and Conceptual Work. Journal of Happiness Studies, 8, 1-14.

Brülde, B. (2007b). Happiness Theories of the Good Life. Journal of Happiness Studies, 8, 15-49.

Crisp, R. 2006. Reasons and the Good. Oxford: Oxford University Press.

Darwall, S. (2002). Welfare and Rational Care. Princeton, NJ: Princeton University Press

De Boer, J. 2013. Scaling Happiness. Philosophical Psychology, Online First, 1-16

Diener, E. and Lucas, R. (1999). Personality and Subjective Well-Being. In: D. Kahneman, E. Diener, \& N. Schwarz (eds.) (1999) pp.213-229.

Diener, E., and Seligman, M.E.P. (2004). Beyond Money: Toward an economy of well-being. Psychological Science in the Public Interest, 5, 1-31.

Dorsey, D. (2010). Three Arguments for Perfectionism. Noûs, 44, 59-79.

Feldman, F. (2004). Pleasure and the Good Life. Oxford: Clarendon Press.

Fletcher, G. (2013). A Fresh Start for the Objective List of Well-Being. Utilitas 25, 206-220.

Frankena, W.K. (1973). Ethics. 2nd ed. XX Prentice-Hall.

Glassen, P. (1957). A Fallacy in Aristotle's Argument about the Good. Philosophical Quarterly 29, 319-322.

Griffin, J. (1986). Well-Being: Its Meaning, Measurement, and Moral Importance. Oxford: Clarendon Press.

${ }^{33}$ Many thanks to Roger Crisp, Julien Deonna, Johanna Seibt, and Fabrice Teroni for their precious comments. 
Harsany, J. C. (1982). Morality and the Theory of Rational Behaviour. In: A. Sen and B. Williams (ed.). Utilitarianism and Beyond. Cambridge: Cambridge University Press, pp.39-62.

Hurka, T. (1987). 'Good’ and 'Good For'. Mind, 96, 71-73

Hurka, T. (1993). Perfectionism. Oxford: Oxford University Press.

Hursthouse, R. (1999). On Virtue Ethics. Oxford: Oxford University Press.

Kagan, S. (1992). The Limits of Well-Being. Social Philosophy and Policy, 9, 169-189.

Kahneman, D. (1999). Objective Happiness. In: Kahneman, Diener, \& Schwarz (eds.), pp.3-25.

Kahneman, D., Diener, E., \& Schwarz, N. (eds.) (1999). Well-Being: The Foundations of Hedonic Psychology. New York: The Russell Sage Foundation.

Kahneman, D., Krueger, A.B. (2006). Developments in the Measurement of Subjective Well-Being. Journal of Economic Perspectives, 20, 3-24.

Katz, L. (2006). Pleasure. In: E. N. Zalta (ed.) (2014). The Stanford Encyclopedia of Philosophy Available at: http://plato.stanford.edu/archives/spr2014/entries/pleasure/ [Accessed 28 March 2014]

Kesebir, P. and Diener E. (2008). In Defense of Happiness: Why Policymakers Should Care about Subjective Well- Being. In: L. Bruni, F. Comim, and M. Pugno (eds.) (2008). Capabilities and Happiness. New York: Oxford University Press, pp.60-80.

Kraut, R. (2007). What is Good and Why: The Ethics of Well-Being. Cambridge, MA: Harvard University Press

Little, I. M. D. (1950). A Critique of Welfare Economics. Oxford: Oxford University Press.

Mill, J. S. (1861). Utilitarianism. Roger Crisp (ed.) (1998). Oxford: Oxford University Press.

Miller, A. (2003). An Introduction to Contemporary Metaethics. Cambridge: Polity Press.

Moore, A., and Crisp, R. (1996). Welfarism in Moral Theory. Australasian Journal of Philosophy, 74, 598-613

Moore, G. E. (1903). Principia Ethica. Revised Edition. Baldwin, T. (ed.)(1993). Cambridge: Cambridge University press.

Nozick, R. (1974). Anarchy, State, and Utopia, Oxford: Basil Blackwell.

Nussbaum, M. (2000). Women and Human Development: The Capabilities Approach. Cambridge: Cambridge University Press.

Overvold, M. C. (1982). Self-Interest and Getting What You Want. In: H. Miller and W. Williams (eds.) (1982). The Limits of Utilitarianism. Minneapolis: University of Minnesota Press, pp.185-194

Parfit, D. (1984). Reasons and Persons. Oxford: Clarendon Press. 
Plato (360 BCE). Philebus. J. M. Cooper (ed.) 1997. Plato: Complete Works. Indianapolis: Hackett.

Plato (380 BCE). Protagoras. J. M. Cooper (ed.) 1997. Plato: Complete Works. Indianapolis: Hackett.

Railton, P. (1986a). Facts and Values. Philosophical Topics, 14, 5-31

Railton, P. (1986b). Moral Realism. Philosophical Review 95, 163-207

Raz, J. (1986). The Morality of Freedom. New York: Oxford University Press.

Raz, J. (2000). The Central Conflict: Morality and Self-Interest. In: R. Crisp and B. Hooker (eds.) (2000). Well-Being and Morality: Essays in Honour of James Griffin. New York: Oxford University Press, pp.209-238.

Regan, D. (2004). Why Am I My Brother's Keeper? In: R. J. Wallace, P. Pettit, S. Scheffler, et al. (eds.) (2004). Reason and Value: Themes from the Moral Philosophy of Joseph Raz. Oxford: Oxford University Press, pp.202-30.

Rodogno, R. (2008). On the Importance of Well-Being. Ethical Theory and Moral Practice, 11, 197212

Rodogno, R. (2010). Sentientism, Well-Being, and Environmentalism. Journal of Applied Philosophy, 27, 84-99.

Rodogno, R. (2014). Well-Being between Science and Philosophy. In: J.H. Søraker, P. Wong , J. Boer, J. De Rijt, P. Brey (eds.) (2014). Well-Being in Contemporary Society. Springer: Berlin.

Rodogno, R. (in press). Happiness and Well-Being. South African Journal of Philosophy

Rosati, C. S. (1995). Persons, Perspectives, and Full Information Accounts of the Good. Ethics, 105, 296-325.

Rosati, C.S. (2000). Brandt's Notion of Therapeutic Agency. Ethics, 110, 780-811.

Rosati, C.S. (2006). Personal Good. In: T. Horgan \& M. Timmons (eds.) (2006). Metaethics After Moore. Oxford: Oxford University Press, pp.107-132.

Rosati, C.S. (2008). Objectivism and Relational Good. Social Philosophy \& Policy, 25, 314-349.

Rosati, C.S. (2009a). Relational Good and the Multiplicity Problem. Philosophical Issues, 19, 205-234.

Rosati, C. S. (2009b). Self-Interest and Self-Sacrifice. Proceedings of the Aristotelian Society, 109, 311325.

Ryan, R. \& Deci, E. (2000). “The 'What' and 'Why' of Goal Pursuits: Human needs and the self determination of behavior. Psychological Inquiry, 11, 227-268.

Ryan, R. Huta, V. \& Deci, E. (2008). Living Well: A Self-Determination Theory Perspective on Eudamonia. Journal of Happiness Studies, 9,139-170.

Ryff, C. \& Singer, B. (1998). 'The Contours of Positive Human Health. Psychological Inquiry, 9, 1-28.

Ryff, C. \& Singer, B. (2008). Know Thyself and Become What You Are: A Eudaimonic Approach to Psychological Well-Being. Journal of Happiness Studies, 9, 13-39. 
Sandvik E, Diener E, Seidlitz L. (1993). Subjective well-being: the convergence and stability of selfreport and non-self-report measures. Journal of Personality, 61, 317-42.

Scanlon, T. (1998). What We Owe to Each Other. Cambridge, Mass., London: Belknap Press of Harvard University Press.

Schimmack, U. \& Oishi, S. (2005). Chronically accessible versus temporarily accessible sources of life satisfaction judgments. Journal of Personality and Social Psychology, 89, 395-406.

Schwarz, N. \& Strack, F. (1999). "Reports of Subjective Well-Being: Judgmental Processes and Their Methodological Implications." In Kahneman, Diener, \& Schwarz (eds.), 61-84.

Sidgwick, H. (1907). The Methods of Ethics. $7^{\text {th }}$ Edition. London: Macmillan.

Skorupski, J. (1999). Ethical Explorations. Oxford: Oxford University Press.

Skorupski, J. (2006). Green and the Idealist Conception of a Person's Good. In: M. Dimova-Cookson \& W. J. Mander (eds.) (2006). T.H. Green: Ethics, Metaphysics, and Political Philosophy. Oxford University Press, pp.47-75.

Sobel, D. (1994). Full Inforamtion Accounts of Well-Being. Ethics, 104, 784-810.

Sumner, W.L. (1996). Welfare, Happiness, and Ethics. Oxford: Oxford University Press.

Tiberius, V. (2006). Well-Being: Psychological Research for Philosophers. Philosophy Compass, 1, 493-505.

Tiberius, V. (2007). Substance and procedure in theories of prudential value. Australasian Journal of Philosophy, 85, 373-391.

Tiberius, V., Plakias, A. (2010). Well-Being. In: J.M. Doris (ed.) (2010). The Moral Psychology Handbook. New York: Oxford University Press, pp.402-432.

Velleman, J. D. (1988). Brandt’s Definition of “Good”. Philosophical Review, 97, 353-371.

Zimmerman, D. 2003. Why Richard Brandt Does Not Need Cognitive Psychotherapy, and Other Glad News about Idealized Preference Theories in Meta-Ethics. Journal of Value Inquiry, 37, 373-394. 